\title{
Improving the Mechanization of High-Quality Seed Production
}

\author{
Orobinsky Vladimir Ivanovich \\ doctor of Agricultural Sciences \\ Head of the Dept. of Agricultural Machinery, tractors and \\ cars, Professor \\ Dean of the Faculty of Rural Engineering \\ Voronezh State Agrarian University after Emperor Peter the \\ Great \\ Voronezh, Russian Federation \\ e-mail: main@agroeng.vsau.ru
}

\section{Gievsky Aleksey Mikhailovich}

doctor of technical Sciences, Professor, the Dept. of

Agricultural Machinery, tractors and cars

Voronezh State Agrarian University after Emperor Peter the Great

Voronezh, Russian Federation

e-mail: aleksej.gievskij@mail.ru

\author{
Tarasenko Alexander Pavlovich \\ doctor of technical Sciences, Professor, the Dept. of \\ Agricultural Machinery, tractors and cars \\ Voronezh State Agrarian University after Emperor Peter the \\ Great \\ Voronezh, Russian Federation \\ e-mail: main@agroeng.vsau.ru
}

\author{
Chernyshov Aleksey Viktorovich \\ candidate of Engineering Sciences, Docent of the \\ department of the Agricultural Machinery, tractors and cars. \\ Voronezh State Agrarian University after Emperor Peter the \\ Great \\ Voronezh, Russian Federation \\ e-mail: lexa-c@yandex.ru
}

\author{
Baskhakov Ivan Vasilyevich \\ candidate of Engineering Sciences, \\ Docent of the department of the Agricultural Machinery, tractors and cars. \\ Voronezh State Agrarian University after Emperor Peter the Great \\ Voronezh, Russian Federation \\ e-mail: vasich2@yandex.ru
}

\begin{abstract}
This paper presents the indicators of quality of the grain obtained by harvesting winter wheat with conventional and rotary combine harvesters. It was identified that rotary combines substantially decrease both shattering and micro-damage to grain. The results of the research indicate that agribusiness enterprises should primarily use rotary combines to harvest seed crops. This, in turn, will allow to raise the qualitative characteristics of the seed grain, reduce the seeding rate and increase the crop yield. During the post-harvesting handling of grain heaps that arrive at the grain cleaning assemblies working according to the fractional flow technology using the universal high-performance machine, it is necessary to separate the forage fraction of grain with seeds less than $2.6 \mathrm{~mm}$. This will allow to remove the air-screen cleaner machine for the secondary cleaning as well as the indented cylinder unit while removing the need for two norias for transporting grain towards them and moving it with the auger in the indented cylinder unit. Coarse impurities and unthreshed grain will be separated by a seed blower. This way, broad use of rotary combine harvesters to harvest cereal crops will allow not only to reduce shattering and micro-damage to seed grain during harvesting but also to simplify the seedcleaning plant, which in turn will lead to reduced costs of postharvest handling of market grain and seeds.
\end{abstract}

Keywords - grain shattering and micro-damage, conventional combines, rotary combines, fractioning technology, reducing energy and material consumption.

\section{INTRODUCTION}

A steady increase in the production of cereal crops is the priority goal of the agricultural industry of the Russian Federation. Gross harvesting of the grain necessary to stock seed reserves, provide the population with high-quality products and the animal farmers with grain forage determines the food security of the country. Timely introduction of innovative technical and technological solutions for harvesting and post-harvest handling will allow to deal with the problems of increasing the production of high-quality seeds and market grain $[1,2]$. The excessively high level of damage to grain during its harvesting and post-harvest handling is the main reason of its decreased germination rate and capacity $[3,4,5$, 6]. Accumulation of large "piles" of unprocessed grain at the threshing floor for prolonged periods of time leads to the reduced quality of the obtained market and seed grain due to the low performance of the grain-cleaning facilities' technological lines. Reducing the level of grain damage during 
harvesting and post-harvest handling and increasing the quality of seed and market grain is possible by means of organizing fractional flow processing of the inbound uncleaned grain from combines. Packing the inbound uncleaned grain at the threshing floor for long-term storage is unacceptable because there it will be subjected to the effects of atmospheric precipitation and microorganisms [71. Grain loaders additionally damage the caryopses by $4-6 \%$ and performing this technological operation leads to increased power consumption per unit of final product while the resulting seeds frequently do not meet the State Standard requirements [8]. In order to decrease the cumulative damage and dangerous types of damage, seed farms need to implement flow processing of all inbound uncleaned grain from combines.

\section{MATERIALS AND METHODS}

This research included identifying such parameters of uncleaned grain coming from different types of combines for post-harvest handling as the content of its components, thousand grain weight, germination rate, vitreousness, and gluten content according to conventional standard techniques.

Use of the gross index of grain damage $\mathrm{T}_{\mathrm{gr}}$, when all types of damage are reduced to one: germ is damaged, allows to present an unbiased estimation of the influence of damage on the sowing qualities of the seeds. It can be determined using the following expression

$$
T_{i \delta}=G_{2}+G_{1} \cdot \frac{b_{1}}{b_{2}}+G_{3} \cdot \frac{b_{3}}{b_{2}}+G_{4} \cdot \frac{b_{4}}{b_{2}}+G_{5} \cdot \frac{b_{5}}{b_{2}}+G_{6} \cdot \frac{b_{6}}{b_{2}},
$$

where $G_{1} \ldots G_{2}$ is the percentage of grains with missing germ, damaged germ, damaged germ envelope, damaged envelope of germ and endosperm, damaged endosperm, damaged endosperm envelope;

$b_{1} \ldots b_{2}-$ are coefficients determined according to the formula:

$$
b_{i}=0.01 \cdot\left(B_{7}-B_{i}\right)
$$

where $B_{7}$ is the germination rate of undamaged grain, $\%$,
$B_{i}$ is the germination rate of grain with the considered types of damage, $\%$.

Many years of research identified that the average germination rate of winter wheat seeds is: $99 \%$ without damage, with damage: germ $-50.8 \%$, endosperm $-60.6 \%$; germ envelope $-85.6 \%$; envelope of germ and endosperm $83.4 \%$; endosperm envelope $-94.4 \%$ [7].

\section{RESUlTS AND DISCUSSION}

Both domestic and imported harvesting combines with both conventional and rotary threshing and separating devices are used to harvest crops in the conditions of Russian agriculture. However, foreign manufacturers have shifted to producing harvesting combines only with rotary threshing and separating devices. Currently prevalent in Russia are conventional combines. Excessively high level of damaged and biologically flawed grain in the total mass inbound for post-harvesting handling significantly complicates obtaining seeds that meet the standards and frequently the food grain, too. Research [9] has identified that 10-15 million tons of grain perish annually due to high levels of damage.

At this stage, an important goal for science and technology is searching for ways of reducing grain damage level during harvest. Combines from such foreign companies as New Holland, John Deere, Case IH, Massey Fergusson, Challenger, and Fendt are more and more often seen in the fields of the Central Black Earth region of Russia along with Russian Torum $740[10,11]$.

To obtain high-quality seeds and market grain used in food production, the uncleaned grain coming from harvesting combines must be immediately divided into the main (seeds and food) and forage fractions. For this reason, it is necessary to use the universal air-screen grain-cleaning machines [16]. Using the UI-ERL-2-1 screen classifier, we separated the samples of uncleaned grain obtained during harvesting winter wheat from rotary and conventional combines into fractions corresponding to screen aperture sizes. The results of this study are presented in Table 1 .

\begin{tabular}{|c|c|c|c|c|c|c|c|c|c|c|}
\hline \multirow{4}{*}{$\begin{array}{c}\text { screen aperture size, } \\
\mathbf{m m}\end{array}$} & \multirow{3}{*}{\multicolumn{2}{|c|}{$\begin{array}{c}\text { Uncleaned mass yielded, } \\
\%\end{array}$}} & \multicolumn{8}{|c|}{ Component distribution, $\%$} \\
\hline & & & \multicolumn{6}{|c|}{ grain } & \multirow{2}{*}{\multicolumn{2}{|c|}{ foreign matter }} \\
\hline & & & \multicolumn{2}{|c|}{ whole } & \multicolumn{2}{|c|}{ shattered } & \multicolumn{2}{|c|}{ in glume } & & \\
\hline & $\mathrm{R}$ & $\mathrm{C}$ & $\mathrm{R}$ & $\mathrm{C}$ & $\mathrm{R}$ & $\mathrm{C}$ & $\mathrm{R}$ & $\mathrm{C}$ & $\mathrm{R}$ & $\mathrm{C}$ \\
\hline 3.2 & 6.71 & 6.58 & 73.11 & 90.11 & 0.03 & 0.05 & 26.71 & 9.93 & 0.16 & 1.78 \\
\hline 3.0 & 29.93 & 28.58 & 97.27 & 97.66 & 0.03 & 0.15 & 2.81 & 1.16 & 0.06 & 0.09 \\
\hline 2.8 & 25.78 & 19.11 & 98.95 & 98.89 & 0.04 & 0.41 & 1.06 & 0.65 & 0.02 & 0.03 \\
\hline 2.6 & 27.80 & 28.91 & 99.17 & 98.91 & 0.05 & 0.64 & 0.91 & 0.51 & 0.03 & 0.04 \\
\hline 2.4 & 6.98 & 8.49 & 98.82 & 98.11 & 0.11 & 1.28 & 0.96 & 0.67 & 0.05 & 0.12 \\
\hline 2.2 & 2.61 & 4.21 & 97.65 & 94.68 & 0.77 & 4.11 & 1.71 & 0.62 & 0.26 & 0.91 \\
\hline 2.0 & 0.65 & 3.81 & 91.46 & 68.12 & 5.57 & 26.42 & 3.41 & 0.51 & 0.71 & 5.60 \\
\hline 1.8 & 0.15 & 0.18 & 56.42 & 31.21 & 23.14 & 63.88 & 0 & 0 & 22.13 & 4.95 \\
\hline
\end{tabular}

TABLE I. DISTRIBUTION OF UNCLEANED GRAIN MASS AND ITS COMPONENTS IN SCREENS

The data in Table 1 shows that the maximum value of uncleaned grain mass is separated at the screens with the aperture sizes from 2.6 to $3.0 \mathrm{~mm}$. These screens separate
$83.51 \%$ of the mass coming from rotary combines and $76.6 \%$ of that from the conventional ones. Reducing the aperture size increases the separation of shattered grain from 0.03 to 
$23.14 \%$ for rotary combines and from 0.05 to $63.88 \%$ from conventional combines. This can serve as a proof of that conventional combines shatter more grain and is should generally be separated during post-harvesting handling in screens with the aperture size of $<2.4 \mathrm{~mm}$. The quality of market grain and seeds substantially depends on the size of the separated grain (Table 2).

TABLE II. EFFECT OF GRAIN SIZE ON ITS QUALITY

\begin{tabular}{|c|c|c|c|c|c|c|c|c|c|c|}
\hline \multirow{3}{*}{$\begin{array}{l}\text { Screen aperture } \\
\text { size, } \mathbf{m m}\end{array}$} & \multicolumn{10}{|c|}{ Grain quality indicators } \\
\hline & \multicolumn{2}{|c|}{ Thousand grain weight, $g$} & \multicolumn{2}{|c|}{ Gross damage, $\% T_{g r}$} & \multicolumn{2}{|c|}{ Germination rate, $\%$} & \multicolumn{2}{|c|}{ Vitreousness, \% } & \multicolumn{2}{|c|}{ Gluten content, $\%$} \\
\hline & $\mathrm{R}$ & $\mathrm{C}$ & $\mathrm{R}$ & $\mathrm{C}$ & $\mathrm{R}$ & $\mathrm{C}$ & $\mathrm{R}$ & $\mathrm{C}$ & $\mathrm{R}$ & $\mathrm{C}$ \\
\hline 3.2 & 49.4 & 48.4 & 27.98 & 29.28 & 98.1 & 95.2 & 88 & 66 & 38 & 38 \\
\hline 3.0 & 46.8 & 46.2 & 27.41 & 28.88 & 99.6 & 98.1 & 78 & 75 & 37 & 37 \\
\hline 2.8 & 42.7 & 42.2 & 23.54 & 27.65 & 98.6 & 97.2 & 74 & 65 & 35 & 35 \\
\hline 2.6 & 36.3 & 36.1 & 28.29 & 29.68 & 98.2 & 96.6 & 60 & 58 & 34 & 34 \\
\hline 2.4 & 28.2 & 27.4 & 29.51 & 30.61 & 95.8 & 94.1 & 46 & 44 & 31 & 31 \\
\hline 2.2 & 22.5 & 20.2 & 30.25 & 31.89 & 94.6 & 92.3 & 35 & 28 & 27 & 27 \\
\hline 2.0 & 16.1 & 15.5 & 31.11 & 33.58 & 92.7 & 90.5 & 18 & 16 & 26 & 26 \\
\hline 1.8 & 10.1 & 9.4 & 32.91 & 34.62 & 85.4 & 80.1 & 12 & 10 & 22 & 22 \\
\hline
\end{tabular}

The data from the research presented in Table 2 shows that with the decrease in thousand gain weight is accompanied with the decrease in germination rate, vitreousness, and gluten content, and gross damage first decreases, then rises. The minimal gross damage matches the caryopses separated at the screens with the aperture size of $2.8 \mathrm{~mm}$. The damage to caryopses separated from the mass coming from rotary combines is on average $1.90 \%$ less as compared with conventional combines. This leads to the average increase in germination rate by $2.37 \%$ and to the $9.13 \%$ increase in vitreousness. The screen with the aperture size of $<2.6 \mathrm{~mm}$ separates the grain with the thousand grain weight of 27.4$28.2 \mathrm{~g}$ with the vitreousness of $44-46 \%$ and gluten content no more than $31 \%$. This means that in order to obtain highquality seeds and market grain, it is necessary to use sorting screens with the aperture size of at least $2.6 \mathrm{~mm}$.

The specifics of the design of the threshing and separating device (TSD), its operation modes, and the intensity of the mechanical impact on the grain during harvesting also determines the quality of market and seed grain.

Table 3 shows the results of the study of the quality of winter wheat grain obtained from conventional and rotary combines during winter wheat harvest at different TSD rotation velocities.

TABLE III. QUALITY OF GRAIN OBTAINED FROM CONVENTIONAL AND ROTARY COMBINES DURING WINTER WHEAT HARVEST

\begin{tabular}{|c|c|c|c|c|c|c|}
\hline Combine make & TSD type & Rotor (drum) rotation velocity & \multicolumn{3}{|c|}{ Grain content in uncleaned mass, \% } \\
\cline { 3 - 7 } & & min-1 & whole & shattered & in glume & damaged \\
\hline John Deere 9880 & rotary & 600 & 96.68 & 0.04 & 3.04 & 24.71 \\
& & 700 & 96.81 & 0.08 & 2.41 & 23.82 \\
& & 800 & 96.52 & 0.13 & 2.14 & 25.61 \\
\hline John Deere 9660 & conventiona & 600 & 97.58 & 0.82 & 1.51 & 25.41 \\
& & 700 & 97.45 & 1.41 & 1.42 & 25.62 \\
& & 800 & 97.28 & 1.48 & 0.91 & 27.92 \\
\hline New Holland CR 9080 & rotary & 600 & 96.74 & 0.07 & 3.11 & 21.38 \\
& & 700 & 96.82 & 0.04 & 3.15 & 22.00 \\
& & 800 & 96.68 & 0.03 & 3.24 & 22.81 \\
\hline New Holland CS 660 & conventiona & 600 & 96.51 & 0.84 & 2.21 & 26.41 \\
& & 700 & 96.84 & 0.81 & 1.22 & 27.94 \\
& & 800 & 96.32 & 1.57 & 1.11 & 28.21 \\
\hline Torum 740 & rotary & 600 & 69.21 & 0.69 & 30.83 & 25.29 \\
& & 700 & 70.64 & 0.72 & 28.12 & 27.11 \\
& & 800 & 92.41 & 0.92 & 10.31 & 26.54 \\
\hline Palesse GS-12 & conventiona & 600 & 92.85 & 2.84 & 3.01 & 38.41 \\
& & 700 & 94.74 & 3.21 & 2.88 & 40.71 \\
& & 800 & 3.45 & 2.84 & 41.91 \\
\hline
\end{tabular}

Table 3 indicates that the lowest shattering and microdamaging of grain was achieved during harvesting winter wheat with New Holland CR 9080 rotary combines while the highest value was produced by Palesse GS-12 combine. Rotor rotation velocity has a significant impact on the content of grains in glume in the uncleaned mass. To decrease the proportion of grains in glume in the uncleaned grain mass, it is necessary to increase the rotor velocity, which can be easily controlled in the field. Increasing the rotor velocity leads to increased shattering and micro-damaging of grain. It should be noted that caryopses with missing germ are virtually absent in the samples obtained from rotary combines at the velocity of $800 \mathrm{~min}-1$. Analysis of the data indicates that the level of shattering and damage of the grain harvested by John Deere combines due to the fact that its design includes the lifting beater of the accelerator of grain feed to the threshing and 
separating device and the augers for transporting uncleaned grain for cleaning, which all increase the intensity of mechanical impact on caryopses. When comparing the quality of threshing by Torum 740 and New Holland CR 9080 combines, one should note the increase of shattering and micro-damage due to the increased volume and intensity of the impact on the grain in the inclined chamber. The maximum thousand grain weight during winter wheat harvesting was $38.6 \mathrm{~g}$ for John Deere, $37.4 \mathrm{~g}$ for New Holland, $26.3 \mathrm{~g}$ for Torum 740, and $35.4 \mathrm{~g}$ for Palesse GS-12.

Analysis of the research data indicates that use of rotary combines for harvesting winter wheat allows to substantially decrease both the shattering and the micro-damage done to grain in the process, which is especially important for harvesting seed crops. Comparing the parameters of threshing quality of New Holland CS 660 conventional combine with the rotary New Holland CR 9080, John Deere 9880, and Torum 740 makes it clear that using the rotary design allows to decrease average grain shattering $21.4,13.4$ and 1.5 and its micro-damaging 1.24, 1.11 and 1.05 times respectively.

The results of the research indicate that agribusiness enterprises should primarily use rotary combines to harvest seed crops. This, in turn, will allow to raise the qualitative characteristics of the seed grain, reduce the seeding rate and increase the crop yield.

Effect of the rotor or drum velocity $\mathrm{n}$ on grain shattering by combines: rotary $D_{r}$ and conventional $D_{c}$ is described by equations (2) and (3) with sufficient accuracy:

$$
\begin{aligned}
& \mathrm{Dr}=-4.299+251.4 \cdot 10-4 \cdot \mathrm{n}-46.64 \cdot 10-6 \cdot \mathrm{n} 2+0.287 \cdot 10-7 \cdot \mathrm{n} 3 \\
& \mathrm{Dr}=3.364-0.2406 \cdot 10-4 \cdot \mathrm{n}-24.06 \cdot 10-6 \cdot \mathrm{n} 2+0.2765 \cdot 10-7 \cdot \mathrm{n} 3
\end{aligned}
$$

Gross damage of grain by combines: rotary Tgr.r and conventional Tgr.c is described by equations (4) and (5):

$$
\begin{aligned}
& \text { Tgr.r }=16.3-43.35 \cdot 10-4 \cdot \mathrm{n}+21.75 \cdot 10-6 \cdot \mathrm{n} 2 \\
& \text { Tgr.c }=20.97+0.1302 \cdot 10-4 \cdot \mathrm{n}+13.02 \cdot 10-6 \cdot \mathrm{n} 2
\end{aligned}
$$

The obtained expressions allow to determine the degree of shattering and gross damage of the grain mass depending on the combine type and the operation mode of its TSD.

Analyzing the research above illustrates that harvesting cereal crops with rotary combines allows to significantly reduce the degree of grain shattering and micro-damage during the harvest. Furthermore, it is necessary to separate the forage fraction of grain with seeds less than $2.6 \mathrm{~mm}$ during the post-harvesting handling of grain heaps that arrive at the grain cleaning assemblies working according to the fractional flow technology using the universal high-performance machine. This will allow to remove the air-screen cleaner machine for the secondary cleaning as well as the indented cylinder unit while removing the need for two norias for transporting grain towards them and moving it with the auger in the indented cylinder unit. Large fractions and unthreshed grain will be separated by the seed blower $[12,13,14,15]$. Such an arrangement of machines in the technological line for postharvest handling will allow to decrease the length of the line, which will, in turn, lead to a decrease in the volume and intensity of mechanical impact on grain and will naturally increase the sowing qualities of the obtained seeds. Introducing the proposed design changes and equipping the gain-cleaning plant with the proposed machines will allow to significantly reduce the power and material consumption of handling uncleaned grain.

This way, broad use of rotary combine harvesters to harvest cereal crops will allow not only to reduce shattering and micro-damage to seed grain during harvesting but also to simplify the seed-cleaning plant, which in turn will lead to reduced costs of post-harvest handling of market grain and seeds.

\section{References}

[1] V.I. Aniskin, V.M. Drincha and I.A. Pehalsky, "Damage to the seed crops during the machining", J. Agrarian Science, 1992, vol. 1, pp. 97 105.

[2] V.M. Drincha, Research of seed separation and development of machine technologies for their preparation 2006,p. 384.

[3] Y.M. Erov, E.G. Nurullin, H.Z. Karimov and D.Z. Salahiev. Innovations in the Post-harvest Processing of Grain and Seed. Moscow: Slovo, 2009, p. 103.

[4] Reducing of the Mechanical Damage during Harvesting and Grain Handling: Recommendations, 1988, p. 21.

[5] Russian Standartization Service, Seeds of Agricultural Plants. Varietal and Sowing Quality, GOST R 52325-2005, 2005.

[6] U.F. Lachuga, A.U. Izmailov and A.N. Ziulin, "High-efficiency resource and energy saving technologies and technical tools of grain postharvest treatment”, J. Agricultural Machinery and Technologies, 2009, vol. 1, pp. 2-9.

[7] V.I. Orobinsky, "Influence of microorganisms and keeping period on sowing qualities of seeds", J. Mechanization and electrification of agriculture, 2006, vol. 11, pp. 5-6.

[8] V.I. Orobinsky, "Influence of sieve pattern in sieve pan on fractionation of grain heap", J. Techniques in agriculture, 2012, vol. 3, pp. 32-34.

[9] A.N. Pugachev, Grain damage caused by machines. Moscow: Kolos, 1976, p. 156.

[10] V.P. Pyanykh and S.A. Rodimtsev, "Reducing of the grain damage during the thrashing", J. Mechanization and electrification of agriculture, 2000, vol. 12, pp. 4-6.

[11] A.P. Tarasenko, M.E. Merchalova and D.N. Mironenko, "Improving of mechanization of postharvest seeds treatment", J. Tractors and agricultural machinery, 2006, vol. 1, pp. 50-52.

[12] A.P. Tarasenko, V.I. Orobinsky, M.E. Merchalova A.V, Chernyshov and N.N. Sorokin, "Fractionation of Grain Heap on Sieves", J. Agricultural machines and technologies, 2006, vol. 5, pp. 26-29.

[13] A.P. Tarasenko, V.I. Orobinsky and M.E. Merchalova, "Innovative ways of improving grain postharvest treatment", J. of forestry engineering, 2013, vol. 1, pp. 83-85.

[14] A.P. Tarasenko, Rotary combine harvesters. Moscow: Lan, 2013, p. 188.

[15] E. V. Truflyak, I.I. Trubilin. Modern combine harvesters, 2013, p. 319.

[16] A.M. Gievsky, V.I. Orobinsky, A.P. Tarasenko, A.V. Chernyshov, D.O. Kurilov, "Substantiation of basic scheme of grain cleaning machine for preparation of agricultural crops seeds", IOP Conference Series: Materials Science and Engineering, art. 042035, 2018. 